\title{
Comparison of Complications from Radical Cystectomy between Old-Old versus Oldest-Old Patients
}

\author{
Evi Comploj $^{\mathrm{a}}$ Jeremy West ${ }^{\mathrm{c}}$ Michael Mian ${ }^{\mathrm{b}, \mathrm{g}}$ Luis Alex Kluth ${ }^{\mathrm{d}}$ \\ Alexander Karl $^{\mathrm{e}}$ Christopher Dechet ${ }^{\mathrm{a}, \mathrm{c}}$ Shahrokh F. Shariat ${ }^{\mathrm{i}}$ Christian G. Stief $^{\mathrm{e}}$ \\ Emanuela Trenti $^{a}$ Salvatore Palermo ${ }^{a}$ Michele Lodde ${ }^{a}$ Wolfgang Horninger ${ }^{f}$ \\ Stephan Madersbacher ${ }^{\mathrm{h}}$ Armin Pycha $^{\mathrm{a}}$ \\ ${ }^{a}$ Department of Urology and bivision of Hematology, Central Hospital of Bolzano, Bolzano, Italy; \\ 'Huntsman Cancer Institute, Division of Urology, University of Utah, Salt Lake City, Utah, and \\ ${ }^{d}$ Department of Urology, Weill Cornell Medical College, New York, N.Y., USA; ${ }^{e}$ Department of Urology, \\ Ludwig Maximilians University, Munich, Germany; Departments of fUrology and Pediatric Urology and \\ gHematology and Oncology, Medical University Innsbruck, Innsbruck, hDepartment of Urology and \\ Andrology, Donauspital, and 'Department of Urology, Medical University Vienna, Vienna, Austria
}

\section{Key Words}

Elderly · Radical cystectomy · Bladder cancer .

Complications $\cdot$ Clavien-Dindo classification

\begin{abstract}
Introduction: The purpose of this study was to evaluate and compare complications after radical cystectomy in patients aged $\geq 75$ years. Materials and Methods: 251 patients aged 75-95 years (median 79) underwent radical cystectomy between 2000 and 2012 at four institutions. The patients were divided into two groups: $\geq 75-84$ years of age (group 1 ) versus $\geq 85$ years of age (group 2). Comorbidities, body mass index, and complications were obtained retrospectively, except at the Central Hospital of Bolzano and Weill Cornell Medical Center, which collected data prospectively. Cancerspecific survival, overall mortality, hospital stay, clinical outcome and complications were assessed. Complications were
\end{abstract}

categorized using the Clavien-Dindo classification reporting system. The mean follow-up was 21 months. Results: The median hospital stay was 17 (2-91) days. Perioperative Clavien-Dindo grade $\geq$ III complications were seen in $24.1 \%$ (48/199) of group 1 patients and 19.2\% (10/52) of group 2 patients ( $p=0.045$ ). 30- and 90-day mortality was 4.5 and $13.5 \%$ in group 1 and 6.5 and $32.3 \%$ in group 2, respectively. Only the 90-day mortality rate was statistically significant ( $p<0.05$ ) between the two groups. The 3-year overall survival was $40 \%$ in group 1 and $34 \%$ in group 2 . The 3 -year cancer-specific survival was $52 \%$ in group 1 and $50 \%$ in group 2. Conclusions: We evaluated a large series of elderly ( $\geq 75$ years) patients undergoing radical cystectomy at four institutions. Comparing patients aged $\geq 75-84$ and $\geq 85$ years revealed no significant difference in complications, 30-day mortality, overall and cancer-specific survival rates. Only 90-day mortality rates were significantly higher in the $\geq 85$-year-old patients. (c) 2014 S. Karger AG, Basel

\section{KARGER 125}

(c) 2014 S. Karger AG, Base

$0042-1138 / 14 / 0941-0025 \$ 39.50 / 0$

E-Mail karger@karger.com

www.karger.com/uin
Evi Comploj, MD, FEBU, FEAPU

Department of Urology, Central Hospital of Bolzano

Lorenz Böhler Street 5

IT-39100 Bolzano (Italy)

E-Mail complojevi94@yahoo.de 


\section{Introduction}

Bladder cancer (BC) is a disease of the elderly with a peak incidence at 85 years [1]. Over the last five decades, demographic changes have taken place in Western countries resulting in an aging population. As life expectancy increases, it is estimated that in 20 years nearly half of the population will be considered elderly and that by 2030 , the number of octogenarians will be 3 -fold higher than today [2]. As the peak incidence of $\mathrm{BC}$ is not reached until 85 years of age, the incidence of $\mathrm{BC}$, including muscle-invasive $B C$, will increase with this aging population [3-6].

Currently, radical cystectomy (RC) remains the gold standard for the treatment of muscle-invasive BC [7]. Improvements in surgical and pre- and postoperative care have occurred making RC a safer procedure even in elderly patients [8], it is however often avoided due to concerns about higher morbidity and mortality rates [3]. Hollenbeck et al. [9] reported that aggressive surgical management of BC in elderly patients may improve survival, but the optimal management of elderly patients with muscle-invasive $\mathrm{BC}$ is controversial [10-12].

$\mathrm{RC}$ is not a surgical intervention without risks. Large contemporary series with an average age of approximately 63 years show complication rates of $24-61 \%$ and 90 day mortality rates of approximately $10-37 \%[1,13]$. Due to increased comorbidities, decreased physiological reserve and decreased ability to respond to stressors, elderly patients have an increased risk of complications [14, 15]. This risk must be weighed against the risk of cancer recurrence and progression. Unfortunately, if left untreated, only $14 \%$ of patients with muscle-invasive BC will survive beyond 2 years [1].

Patients $\geq 65$ years are considered elderly. Elderly patients are often subdivided into three categories: youngold (65-74 years of age), old-old ( $\geq 75-84$ years of age) and oldest-old ( $\geq 85$ years of age) $[16,17]$. We hypothesized that the oldest-old RC patients have a higher rate of complications compared to the old-old. To test this hypothesis, we analyzed patients $\geq 75$ years who were treated with $\mathrm{RC}$ at four separate institutions for invasive BC; group 1 included patients aged $\geq 75-84$ years (old-old) and group 2 included patients aged $\geq 85$ years (oldest-old).

\section{Materials and Methods}

All four submitting institutions obtained institutional review board approval. Out of 536 ( $\geq 75$ years) patients only a complete follow-up was available for 251, which was the cohort that underwent RC with removal of regional lymph nodes between 2000 and
2012. The follow-up schedule was conducted in all four institutions in accordance with the EAU guidelines for BC [18].

The Central Hospital of Bolzano and Weill Cornell Medical Center collected their data prospectively, while the Huntsman Cancer Institute at the University of Utah and the Ludwig Maximilians University collected their data retrospectively. The patients were subdivided into two groups: group 1 old-old ( $\geq 75-84$ years of age; mean and median 78 years; $n=199,79.3 \%$ ) and group 2 oldest-old ( $\geq 85$ years of age; range $85-94$ years; mean and median 87 years; $\mathrm{n}=52$ patients, $20.3 \%$ ).

The following clinical parameters were evaluated in this study: age, body mass index (BMI), comorbidities, the American Society of Anesthesiologists (ASA) score, ECOG score and complications. All complications occurring within 1 year of surgery were recorded, defined and graded according the Clavien-Dindo classification (CDC) system [19]. Complications were divided into early (0-30 days after RC), delayed (31-90 days after RC) and late complications (91-365 days after RC).

A $\chi^{2}$ was performed to assess differences between categorical variables and the Mann-Whitney $U$ test for continuous variables. Overall survival and cancer-specific survival were plotted using the Kaplan-Meier methodology. A log-rank test was employed to assess the impact of categorical variables on survival. Multivariate logistic regression models to evaluate the impact of possible risk factors (age $>75$, chronic obstructive pulmonary disease (COPD), $\mathrm{BMI}$, prior abdominal surgery, peripheral vascular disease, hypertension, diabetes mellitus, ASA score $>2$, ECOG score $>1$ and kind of urinary diversion) on 30- and 90-day mortality and CDC III-IV were performed.

A p value of $<0.05$ was considered statistically significant. All statistical analyses were performed with the SPSS software version 17.0.1 (SPSS, Inc., Chicago, Ill., USA). All tests are two-sided.

\section{Results}

\section{Patient Characteristics}

Table 1 shows the characteristics of both groups. There were 46 females and 205 males with a mean age of 80.7 years (median 79). Overall, 240 patients underwent RC and 11 underwent partial cystectomy with dissection of the regional lymph nodes (range 2-43 lymph nodes, median 11). Median follow-up for the entire cohort was 12 months (range $1-127$, mean 21 ). $34 \%$ of group 1 and $58 \%$ of group 2 had an ASA score $\geq 3(\mathrm{p}=0.002)$. There were no statistically significant differences between the groups with regard to prior abdominal surgery, COPD, abdominal aortic aneurysm, hypertension, diabetes or ECOG scores. Of 251 patients, 2 received a neoadjuvant and 1 an adjuvant chemotherapy; the rest of the patients (248/251; $98.8 \%$ ) had no adjuvant or neoadjuvant chemotherapy.

\section{Therapeutic Interventions}

Urinary diversions performed were as follows: ileum conduit in 144, uretero- ureterocutaneostomy in 46, neo- 
Table 1. Patient characteristics

\begin{tabular}{|c|c|c|c|c|}
\hline & Entire cohort & Group 1 & Group 2 & $\mathrm{p}$ value \\
\hline Patients, $\mathrm{n}$ & 251 & 199 & 52 & \\
\hline Age at RC, years, median (range) & $79(75-95)$ & $79(75-84)$ & $87(85-95)$ & \\
\hline Male gender, n (\%) & $205(81.7)$ & $162(81.4)$ & $43(82.7)$ & 0.831 \\
\hline BMI, median (range) & $24.6(15.2-40.89)$ & $25(16.7-40.89)$ & $23.3(15.2-34.54)$ & \\
\hline COPD, n (\%) & $43(17.1)$ & $35(17.6)$ & $8(15.4)$ & 0.707 \\
\hline Abdominal aortic aneurysm, $\mathrm{n}(\%)$ & $17(6.7)$ & $13(6.5)$ & $4(7.7)$ & 0.767 \\
\hline Peripheral vascular disease, $\mathrm{n}(\%)$ & $31(12.3)$ & $24(12.1)$ & $7(13.5)$ & 0.785 \\
\hline Diabetes mellitus, $\mathrm{n}(\%)$ & $43(17)$ & $36(18)$ & $7(13.4)$ & 0.430 \\
\hline Hypertension, $\mathrm{n}(\%)$ & $114(45.4)$ & $91(45.7)$ & $23(44.2)$ & 0.847 \\
\hline ASA score >2, n (\%) & & $67(33.7)$ & $30(57.7)$ & 0.002 \\
\hline ECOG score >1, n (\%) & $83(33)$ & $65(32.7)$ & $18(34.6)$ & 0.790 \\
\hline \multicolumn{5}{|l|}{$\mathrm{pT}(\mathrm{RC})$} \\
\hline pT4 & 31 & 24 & 7 & \\
\hline pTis & 17 & 14 & 3 & \\
\hline Cis present, $\mathrm{n}$ & 90 & 72 & 18 & \\
\hline
\end{tabular}

Table 2. Clinical characteristics

\begin{tabular}{|c|c|c|c|c|}
\hline & Entire cohort & Group 1 & Group 2 & $\mathrm{p}$ value \\
\hline Cumulative hospital stay, median (range) & $17(2-91)$ & $18(2-91)$ & $17(4-51)$ & 0.194 \\
\hline 30 -day mortality, n (\%) & $7 / 142(4.9)$ & $5 / 111(4.5)$ & 2/31 (6.5) & 0.658 \\
\hline Without complications, $\mathrm{n}(\%)$ & $112(44.6)$ & $95(47.7)$ & $17(32.7)$ & 0.052 \\
\hline CDC, $\mathrm{n}(\%)$ & $139(55.4)$ & & & 0.045 \\
\hline $\mathrm{I}$ & $17(6.8)$ & $13(6.5)$ & $4(7.7)$ & \\
\hline III & $38(15.1)$ & $34(17)$ & $4(7.7)$ & \\
\hline IV & $13(5.2)$ & $9(4.5)$ & $4(7.7)$ & \\
\hline $\mathrm{V}$ & $7(2.3)$ & $5(2.5)$ & $2(3.8)$ & \\
\hline 3-year overall survival, \% & & 40 & 34 & 0.097 \\
\hline 3-year cancer-specific survival, \% & & 52 & 50 & 0.537 \\
\hline
\end{tabular}

bladder in 10, and colon conduit in 40 patients. Urinary diversions/surgical approach in the two groups were as follows: for group 1: ileum conduit in 108 (54.27\%), uretero-ureterocutaneostomy in 35 (17.59\%), neobladder in $10(5.03 \%)$, colon conduit in 37 (18.59\%), and partial cystectomy in $9(4.52 \%)$ patients, and for group 2: ileum conduit in $36(69.23 \%)$, uretero-ureterocutaneostomy in $11(21.15 \%)$, neobladder in $0(0 \%)$, colon conduit in 3 $(5.77 \%)$, and partial cystectomy in $2(3.85 \%)$ patients.

Complications from Radical Cystectomy

\section{Hospital Stay and Mortality Rates}

Median length of hospital stay was 18 days in group 1 and 17 days in group 2. 30- and 90-day mortality of the entire cohort was $4.9 \%(7 / 142)$ and $17.6 \%$ (25/142), respectively.

In group 1, 118/199 patients (59.3\%) died during follow-up (range 1-127 months) of which 62.7\% (74/118) died from BC progression. 30- and 90-day mortality in group 1 was $4.5 \%(5 / 111)$ and $13.5 \%$ (15/111), respec- 


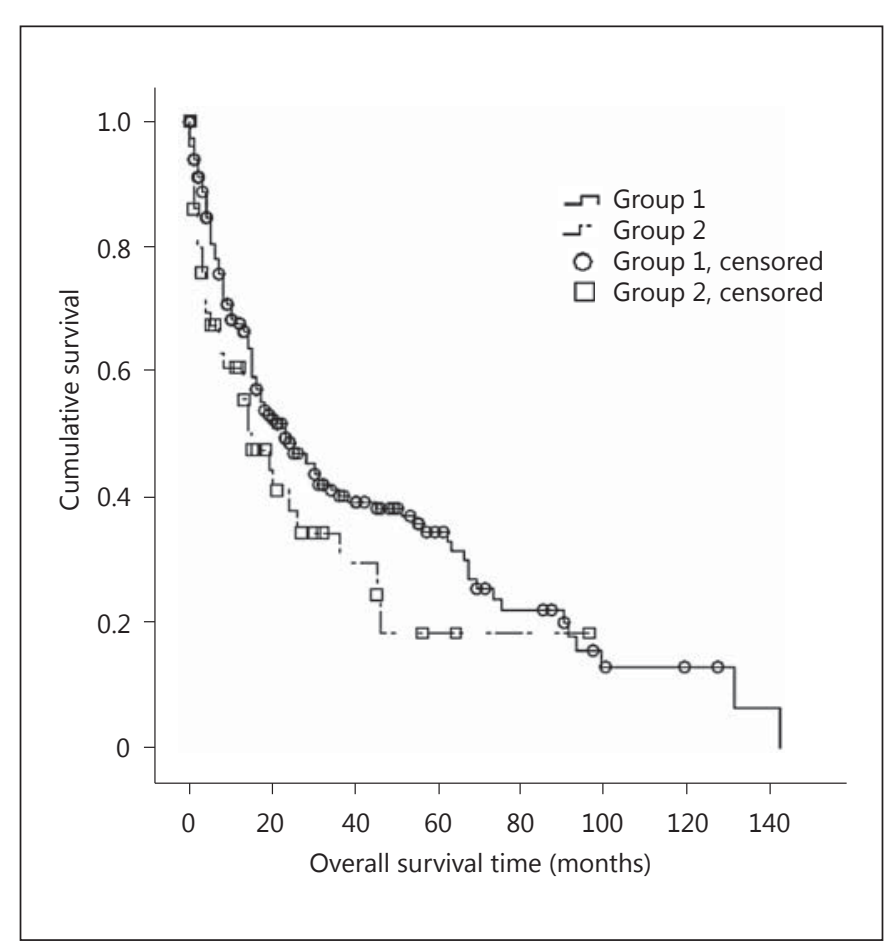

Fig. 1. Three-year overall survival.

tively. In group 2, 31/52 patients (59.6\%) died during follow-up of which $54.8 \%$ (17/31) died of BC progression. 30 - and 90-day mortality in group 2 was $6.5 \%$ $(2 / 31)$ and $32.3 \%(10 / 31)$, respectively. In multivariate logistic regression none of the clinical parameters assessed at the time of diagnosis influenced significantly 30-day mortality, while the presence of COPD and an age of $>84$ years were significant prognosticators for 90 day mortality.

The estimated 3 -year overall survival rate was $40 \%$ in group 1 and $34 \%$ in group $2(\mathrm{p}=0.097)$. The estimated 3 -year cancer-specific survival rate was $52 \%$ in group 1 and $50 \%$ in group $2(\mathrm{p}=0.537)$ (table 2$)$. These differences were not statistically significant (fig. 1,2).

\section{Complications}

Of the entire cohort, $55.4 \%$ (139/251 patients) had at least one complication (CDC I-V). In groups 1 and 2, $52.3 \%(104 / 199)$ and $67.3 \%$ had at least one complication (CDC I-V), respectively. CDC grade $\geq$ III complications were noted in $23 \%(58 / 251)$ of patients: $24.1 \%(48 / 199)$ in group 1 and $19.2 \%(10 / 52)$ in group 2 (table 2). We subdivided complications with $\mathrm{CDC}$ grade $\geq$ III into early complications ( 0 -30 days after RC), delayed complica-

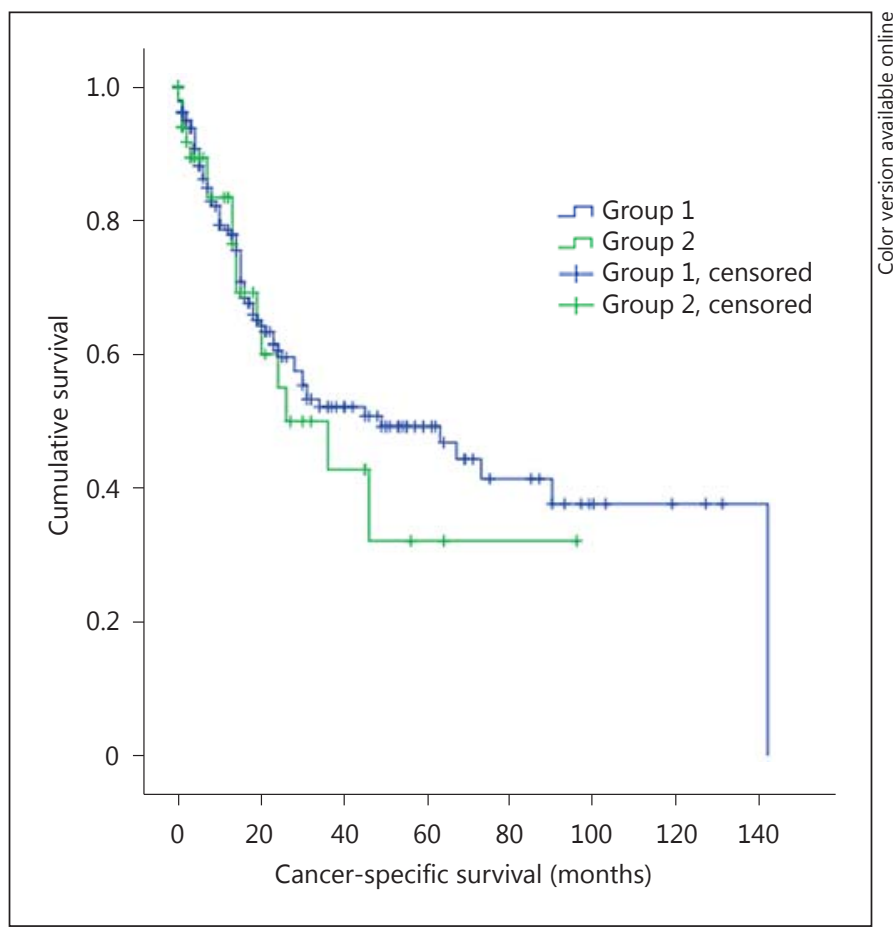

Fig. 2. Three-year cancer-specific survival of the complete study group.

tions (31-90 days after RC) and late complications (91365 days after $\mathrm{RC}$ ). The majority of major complications (CDC grade $\geq$ III) occurred in the first 30 days following $\mathrm{RC}$, but there was no statistically significant difference between both groups. In multivariate logistic regression, of the clinical parameters assessed at time of diagnosis, only prior abdominal surgery influenced significantly CDC grade III-IV.

\section{Discussion}

In the coming decades, demographic changes in Western countries will result in a further aging population [20]. The incidence of $\mathrm{BC}$ also increases with age and is 11 -fold higher in patients $\geq 65$ years compared to patients $<65$ years. In addition, elderly patients ( $\geq 65$ years) have a 16 -fold higher $\mathrm{BC}$ mortality rate compared to patients $<65$ years, and this increases with advanced age [20-22]. Age also represents a strong and independent risk factor for the presence of $\mathrm{BC}$, as the peak age for $\mathrm{BC}$ is advancing and now estimated at 85 years [20,22]. Elderly patients with increased comorbidities, decreased physiologic reserve and advanced tumor stage present 
a therapeutic dilemma [14]. Although RC remains the gold standard for the treatment of muscle-invasive BC [7], analyses of SEER data show that only $12 \%$ of octogenarians with invasive $\mathrm{BC}$ undergo radical surgery. This is presumably due to the concerns of increased morbidity and mortality with surgery in the elderly population which can easily outweigh the benefit of surgical extirpation [23].

Contemporary mortality and morbidity rates of patients undergoing $\mathrm{RC}$ are lower than in previous decades $[24,25]$. Prior to 1990 , the perioperative mortality in large series (>100 subjects) ranged from 2.4 to $15 \%$. Over the past decade, these rates have been reduced to approximately $0-3.9 \%$ [25]. Little is known however about mortality and morbidity rates in the elderly population treated with RC. Although it is reported that RC in the elderly population provides similar disease control and survival outcomes as it does in younger cohorts $[9,23]$, large series of patients are not available. An age over 70 years has been suggested to be a risk factor for higher complication rates [14,25-28], although it seems proper patient selection here is more important than chronological age alone [27].

The CDC is the most commonly used system to define and grade postsurgical complications [19]. In our study, overall 139 patients (55.4\%) suffered a CDC (I-IV) complication. This is comparable with results reporting morbidity rates of patients undergoing RC in the range of 29$61 \%[8,23]$. In group 2 (>85 years old) the rate of CDC grade II complications was two times higher as than in group 1 . However, $>33.3 \%$ in group 2 had blood transfusions for anemia prior to surgery, compared to $20 \%$ in group 1.

Concentrating on major complications (CDC grade $\geq$ III) there was no significant difference between group 1 (24.1\%) and group 2 (19.2\%). However, group 2 had significantly less patients (52 vs. 199) and this lack of difference could reflect a selection bias.

A significant difference was seen in the 90- day mortality rate between patients aged $\geq 75-84$ and $\geq 85$ years. The 90 -day mortality rate in group 2 increased 5 -fold in comparison to the 30-day mortality rate in this group of patients. In multivariate logistic regression, of the clinical parameters assessed at time of diagnosis, only prior abdominal surgery influenced significantly CDC grade IIIIV. Careful follow-up surveillance is therefore recommended in the first 90 days after RC. This has also been noted by Donat et al. [23] and Tyritzis et al. [13]. The average time of hospitalization between American and European patients was as follows: the European time of hospitalization was between 10 and 90 days (mean 24, median 21) and the American one was between 2 and 51 days (mean 11, median 9 days). Interestingly, the 90-day mortality in the American group is $12 \%$ compared to 8.4\% in the European group, the difference is not statistically significant.

According to the 90-day mortality, overall 15 patients (7.5\%) died in group 1: 4 patients died of a surgically related complication, 4 of reasons not related to BC, 4 for an acute cardiac event, and 3 from a respiratory event. In group 2, 6 patients died of a surgically related complication; 1 following esophageal surgery in another division, 1 due to aspiration pneumonia, and 2 of unknown reasons. In group 1, the surgically related deaths were related to sepsis in all 4 patients. In group 2, death resulted from sepsis in 3 patients, eventration in 1, intestinal anastomotic leak in 1 , and rectal perforation with peritonitis in 1 patient. There are several limitations in our study. All cases were performed in high-volume centers, but in four different countries on two continents, which may be problematic and this may not reflect other institutional results. Proper patient selection, surgery in a high-volume center, experienced nursing care and excellent perioperative management may contribute to the prevention of morbidity and mortality [11]. In addition, in all institutions, some patients were not offered RC, suggesting that these elderly patients are carefully selected. Interestingly, there was no significant difference in the morbidity and mortality rate between the US and European centers suggesting similar selection criteria, surgical treatment and postoperative care. Despite this, the 90-day mortality rates for all patients aged $\geq 75$ years are not significant but a trend and more research is necessary to define who best would benefit from cystectomy or alternative therapy. Adopting a 90-day morbidity and mortality definition might deliver a more realistic picture of the risks of RC. Further studies are necessary to evaluate this aspect.

\section{Conclusion}

We sought to analyze a large series of elderly patients to describe outcomes after RC. Our experience suggest that $\mathrm{RC}$ can be safe and effective in properly selected oldest-old patients ( $>84$ years) with a high 90 -day mortality rate, but no significant difference in overall survival between old-old and oldest-old patients. 


\section{References}

1 Shariat SF, Lee R, Lowrance WT, et al: The effect of age on bladder cancer incidence, prognosis and therapy. Aging Health 2010;6:649659.

2 Shalhoub PJ, Quek ML: Management of bladder cancer in the elderly: clinical decisionmaking and guideline recommendations. Aging Health 2010;6:607-610.

$>3$ Ferlay J, Autier P, Boniol M, et al: Estimates of the cancer incidence and mortality in Europe in 2006. Ann Oncol 2007; 18:581-592.

4 International Agency for Research on Cancer. http://globocan.iarc.fr/6/7/2011.

5 Schulzel M, Saltzstein SL, Downs TM, et al: Late age ( 85 years or older) incidence of bladder cancer. J Urol 2008;179:1302-1306.

6 Statistik Austria: Krebsinzidenz und Krebsmortalität in Österreich. http://www.statistik. at/web_de/Redirect/index.htm? dDocName $=050212$, p 64 .

$\checkmark 7$ Madersbacher S, Hochreiter W, Burkhard F, Thalmann GN, Danuser H, Markwalder R, Studer UE: Radical cystectomy for bladder cancer today - a homogeneous series without neoadjuvant therapy. J Clin Oncol 2003;21: 690-696.

$>8$ Roghmann F, Noldus J, von Bodman C, Holz A, Brock M, Palisaar J: Cystectomy in elderly patients: analysis of complications using the Clavien-Dindo classification. Urologe A 2012;51:1386-1392.

-9 Hollenbeck BK, Miller DC, Taub D, Dunn RL, Underwood W 3rd, Montie JE, Wei JT: Aggressive treatment for bladder cancer is associated with improved overall survival among patients 80 years old or older. Urology 2004; 64:292-297.

10 Shariat SF, Milowsky M, Droller MJ: Bladder cancer in the elderly. Urol Oncol 2009;27: 653-667.
11 Froehner M, Brausi MA, Herr HW, Muto G, Studer U: Complications following radical cystectomy for bladder cancer in the elderly. Eur Urol 2009;56:443-454.

12 Wehrberger C, Berger I, Marszalek M, Ponholzer A, Wehrberger M, Rauchenwald M, Madersbacher S: Bladder preservation in octogenarians with invasive bladder cancer. Urology 2010;75:370-375.

13 Tyritzis SI, Anastasiou I, Stravodimos KG, Alevizopoulos A, Kollias A, Balangas A, Katafigiotis I, Leotsakos I, Mitropoulos D, Constantinides CA: Radical cystectomy over the age of 75 is safe and increases survival. BMC Geriatr 2012;12:18.

14 Shabsigh A, Korets R, Vora KC, et al: Defining early morbidity of radical cystectomy for patients with bladder cancer using a standardized reporting methodology. Eur Urol 2009; 55:164-176.

15 Fairey A, Chetner M, Metcalfe J, Moore R, Todd G, Rourke K, Voaklander D, Estey E: Associations among age, comorbidity and clinical outcomes after radical cystectomy: results from the Alberta Urology Institute radical cystectomy database. J Urol 2008;180:128-134.

16 Shariat SF, Godoy G, Lotan Y, et al: Advanced patients age is associated with inferior cancerspecific survival after radical nephroureterectomy. BJU Int 2010;105:1672-1677.

17 Shariat SF, Sfakianos JP, Droller MJ, et al: The effect of age and gender on bladder cancer: a critical review of the literature. BJU Int 2010; 105:300-308.

18 Witjes JA, Compérat E, Cowan NC, De Santis M, Gakis G, Lebret T, Ribal MJ, Sherif A: Guidelines on Muscle-Invasive and Metastatic Bladder Cancer. European Association of Urology, 2013. http://www.uroweb.org/gls/ pdf/07_Bladder\%20Cancer_LRV2.pdf.
19 Dindo D, Demartines N, Clavien PA: Classification of surgical complications: a new proposal with evaluation in a cohort of 6,336 patients and results of a survey. Ann Surg 2004; 240:205-213.

20 Pycha A, Comploj E: The dilemma of cystectomy in old-old and oldest-old patients. Expert Rev Anticancer Ther 2011;11:18631870.

21 Yancik R, Ganz PA, Varricchio CG, Conley B: Perspectives on comorbidity and cancer in older patients: approaches to expand the knowledge base. J Clin Oncol 2001;19:1147-1151.

22 Messing E: Urothelial tumors of the bladder; in Wein AJ (ed): Campell-Walsh Urology, ed 9. Philadelphia, Elsevier, 2008, p 2409.

23 Donat SM, Siegrist T, Cronin A, Savage C, Milowsky MI, Herr HW: Radical cystectomy in octogenarians - does morbidity outweigh the potential survival benefits? J Urol 2010; 183:2171-2177.

24 Novotny V, Hakenberg OW, Froehner M, et al: Systemic assessment of complications and outcome of radical cystectomy undertaken with curative intent in patients with comorbidity and over 75 years of age. Urol Int 2013; 90:195-201.

25 Kulkarni JN: Perioperative morbidity of radical cystectomy: a review. Indian J Urol 2011; 27:226-232.

26 Hollenbeck BK, Taub DA, Miller DC, Dunn RL, Montie JE, Wei JT: The regionalization of radical cystectomy to specific medical centers. J Urol 2005; 174:1385-1389.

27 Gamé X, Soulié M, Seguin P, Vazzoler N, Tollon C, Pontonnier F, Plante P: Radical cystectomy in patients older than 75 years: assessment of morbidity and mortality. Eur Urol 2001;39:525-529.

28 Lee KL, Freiha F, Presti JC Jr, Gill HS: Gender differences in radical cystectomy: complications and blood loss. Urology 2004;63:10951099. 